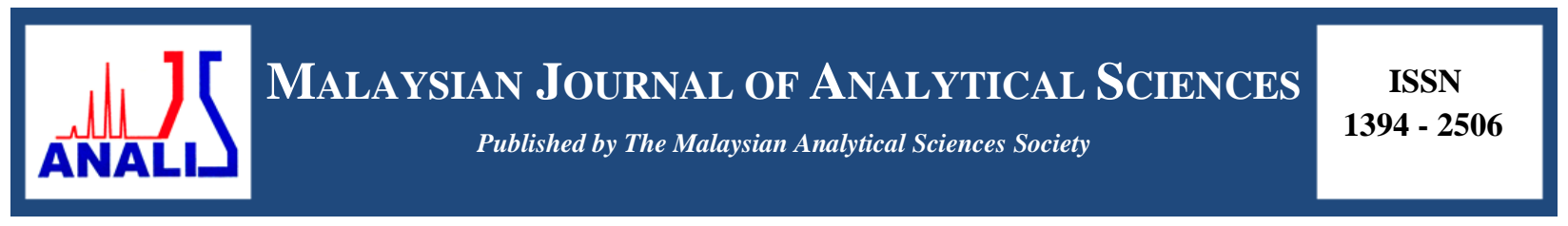

\title{
THE EFFECTS OF GLYCEROL ADDITION TO THE MECHANICAL PROPERTIES OF THERMOPLASTIC FILMS BASED ON JACKFRUIT SEED STARCH
}

\author{
(Kesan Penambahan Gliserol pada Sifat Mekanik Filem Thermoplastik Berdasarkan Kanji Biji \\ Nangka) \\ Nur'Aishah Ahmad Shahrim*, Norshahida Sarifuddin, Hafizah Hanim Mohd Zaki, Ahmad Zahirani Ahmad Azhar \\ Department of Manufacturing and Materials Engineering, \\ International Islamic University Malaysia, 53100 Kuala Lumpur, Malaysia \\ *Corresponding author: aisydahlia@gmail.com
}

Received: 20 July 2017; Accepted: 28 April 2018

\begin{abstract}
Thermoplastic films based on $3 \mathrm{wt} \%$ jackfruit seed starch were prepared using 5 to $30 \mathrm{wt} \%$ glycerol as plasticizer via solution casting method. The aim of this study is to investigate the effect of glycerol on the mechanical properties of films. According to the analysis, the optimum tensile strength of the film was obtained at $4.40 \mathrm{MPa}$, which revealed that the native starch granules were converted into a continuous phase in the presence of glycerol as indicated by scanning electron microscopy. The incorporation of glycerol in starch also showed the formation of hydrogen bond evidenced by Fourier transform infrared spectroscopy.
\end{abstract}

Keywords: starch, jackfruit, glycerol, thermoplastic film

Abstrak

Filem thermoplastik berdasarkan 3 wt.\% kanji biji nangka telah disediakan dengan menggunakan 5 ke 30 wt.\% gliserol sebagai pemplastik melalui kaedah penuangan larutan. Tujuan kajian ini dijalankan adalah untuk menyiasat kesan penambahan gliserol terhadap sifat mekanik filem. Analisis kajian menunjukkan kekuatan tegangan optimum filem diperoleh pada $4.40 \mathrm{MPa}$, yang menunjukkan butir-butir kanji bertukar ke fasa berterusan dengan kehadiran gliserol seperti yang ditunjuk oleh mikroskop imbasan elektron (SEM). Penggabungan gliserol dalam kanji turut menunjukkan pembentukan ikatan hidrogen seperti yang dibuktikan oleh spektroskopi inframerah transformasi Fourier (FTIR).

Kata kunci: kanji, nangka, gliserol, filem thermoplastik

\section{Introduction}

Starch, a natural renewable polysaccharide from numerous diversities of plants, as a raw material to produce biodegradable and eco-friendly plastics has been a topic of interest in many researches. This is driven by the global environmental concern resulted from petroleum-derived plastics, which continue to be prevalent over time [1]. Previously, many researchers concentrated on starches from different sources, such as corn, tapioca, potato, and wheat. So far, there have been very few works reported on starch from non-conventional sources such as jackfruit seed. Hence, in this study, jackfruit seed (Artocarpus heterophyllus) is utilized as a source of starch to develop starch-based films. Jackfruit is one of the most popular tropical fruits that grows abundantly in Asia. In Malaysia, jackfruit seeds are usually thrown away as waste even though the seeds are a potential source of nutrition [2]. 


\section{Nur'Aishah et al: THE EFFECTS OF GLYCEROL ADDITION TO THE MECHANICAL PROPERTIES OF THERMOPLASTIC FILMS BASED ON JACKFRUIT SEED STARCH}

Moreover, jackfruit seeds have a high starch content; seeds content in a jackfruit are about 100 to 500 or approximately 8 to $15 \%$ by weight of a jackfruit [3]. However, this type of starch is classified as a native starch, or in other words, it is not in thermoplastic form.

Starch-based thermoplastic films have a variety of industrial uses, such as for food packaging, compost bags, and coatings [4]. Plasticizer such as polyol should be added to starch since it is natural, inexpensive, and renewable so that the final product is both biodegradable and cost-effective [5]. The incorporation of jackfruit seed starch with glycerol as plasticizer will overcome the native starch drawbacks such as brittleness and high moisture sensitivity and at the same time will enhance the product flexibility and workability, in developing a potential and ecological alternative to the synthetic products [6]. For this reason, it is expected that the modification of jackfruit seed starch with the addition of glycerol as plasticizer will result in high tensile strength and elongation at break of the film due to the reduction of intermolecular forces and an increase in polymer chain mobility as reported elsewhere [7]. However, the optimum amount of glycerol in the jackfruit seed starch has not been reported as yet.

Therefore, the aim of this study is to develop glycerol-plasticized jackfruit seed starch (GTPS) film via solution casting method and to evaluate the effect of glycerol content on the mechanical and physical properties of jackfruit seed starch film.

\section{Materials}

\section{Materials and Methods}

Jackfruit seeds were obtained from Tropical Fruit Farm, Penang, and glycerol (85\% purity) was purchased from Merck Sdn. Bhd. (Selangor, Malaysia).

\section{Preparation of jackfruit seed powder}

Jackfruit seeds were cleaned, peeled, and sliced into thin pieces. Then, the seeds were dried in the oven for 24 hours. The dried seeds were grounded with an electronic kitchen blender for 20 minutes followed by milling (Fritsch, Planetary Ball Mill) at a ratio of $1 \mathrm{~g}$ powder:5 balls for about 1 hour to obtain micro-meter scale size of seeds. Finally, the powder was sieved using $100 \mu \mathrm{m}$ mesh, packed and sealed in a plastic bag, then stored in a refrigerator $\left(<5^{\circ} \mathrm{C}\right)$ until further use.

\section{Extraction of starch from jackfruit seed}

The extraction of jackfruit seed starch (JFSS) was carried out as per the method mentioned by Noor et al. [3] with a slight modification. About $100 \mathrm{ml}$ distilled water was poured into $5 \mathrm{~g}$ of jackfruit seed powder and stirred constantly for 6 to 8 hours at room temperature. The slurry produced was then filtered using 212 mesh sieve and the remaining residues were washed three times with distilled water. Finally, the filtrate wet starches were precipitated overnight at $4{ }^{\circ} \mathrm{C}$ and dried in the oven at $40{ }^{\circ} \mathrm{C}$ for 24 hours. The dry starches obtained were filled in a plastic bag and kept at room temperature until further use.

\section{Preparation of thermoplastic starch film with glycerol}

The fabrication of TPS incorporation with glycerol was carried out via solution casting as proposed by Seligra et al. [8] and Reddy and Yang [9] with a minor modification. Total mass of the system is $100 \mathrm{~g}$ where starch content was fixed at 3 wt.\% and the amount of glycerol varied from 5 to $30 \mathrm{wt} \%$. The materials' abbreviations and corresponding sample compositions are listed in Table 1. The starch and distilled water were mixed and heated up to $90{ }^{\circ} \mathrm{C}$ on a hot plate and held for 20 minutes with a constant stirring speed at $250 \mathrm{rpm}$. Then, the solution was cooled to $65^{\circ} \mathrm{C}$ and glycerol was added to the mixture while stirring continuously for 5 minutes. The film forming solution was casted on acrylic plates and dried for 24 hours in the oven. Later, the thermoplastic film was peeled from the plates and stored in the desiccator maintained at $23{ }^{\circ} \mathrm{C}$ and $30 \%$ relative humidity prior to characterization. 
Table 1. Used symbols and corresponding compositions of each sample

\begin{tabular}{llccc}
\hline \multirow{2}{*}{ Materials } & \multirow{2}{*}{ Abbreviations } & \multicolumn{3}{c}{ Samples } \\
\cline { 3 - 5 } & & Seight Proportions, gram) & Glycerol & Distilled Water \\
\hline GTPS1 & G05 & 3 & 0.5 & 96.5 \\
GTPS2 & G10 & 3 & 1.0 & 96.0 \\
GTPS3 & G15 & 3 & 1.5 & 95.5 \\
GTPS4 & G20 & 3 & 2.0 & 95.0 \\
GTPS5 & G25 & 3 & 2.5 & 94.5 \\
GTPS6 & G30 & 3 & 3.0 & 94.0 \\
\hline
\end{tabular}

\section{X-ray diffraction test}

The diffraction pattern of the JFSS powder was analysed with an X-ray diffractometer (Shimadzu; XRD-6000). The scanning region of the diffraction angle (20) was set from 5 to $40^{\circ}$ at a rate of $3 \% \mathrm{~min}$ of scan speed and the diffractometer was operated at a power of $40 \mathrm{kV}$ and $20 \mathrm{~mA}$.

\section{Mechanical test}

The mechanical properties of the starch films were determined in accordance with ASTM standard D882-02 by using MTS tensile tester (Shimadzu; Material Testing System) with $20 \mathrm{~mm} / \mathrm{min}$ of speed and $5 \mathrm{kN}$ of load. The test was carried out on five samples that were cut manually into strips with a dimension of $70 \mathrm{~mm} \times 10 \mathrm{~mm}$ from the cast films based on the standard ISO-527.

\section{Scanning electron microscopy}

The surface structure of JFSS powder and TPS films were examined using a scanning electron microscope (JEOL, JSM 5600 SEM; JEOL Ltd., Tokyo, Japan). The samples were sputter coated with carbon (Polaron SC515) and observed under SEM at a voltage of $8 \mathrm{kV}$.

\section{Fourier transform infrared spectroscopy analysis}

The infrared (IR) spectra of the JFSS powder and GTPS2 film was recorded on FTIR spectrometer (Spectrum 100 FTIR; PerkinElmer, United States). Measurements were taken in the average of 32 scans per sample between 4000 $\mathrm{cm}^{-1}$ to $600 \mathrm{~cm}^{-1}$ with a resolution of $4 \mathrm{~cm}^{-1}$.

\section{X-ray diffraction analysis}

\section{Results and Discussion}

The XRD pattern obtained with the JFSS granules is shown in Figure 1. The broad diffraction peaks can be related to the amorphous characteristic of starch. The appearances of peaks of $2 \theta$ at $15.37^{\circ}, 22.97^{\circ}$, and $23.57^{\circ}$ indicating the presence of type-A starch in jackfruit seed since there is no peak in the range of $5^{\circ}-6^{\circ}$. In fact, jackfruit seed contains a high amount of starch and the amylose content is about $32 \%$ as reported by Theivasanthi and Alagar [10].

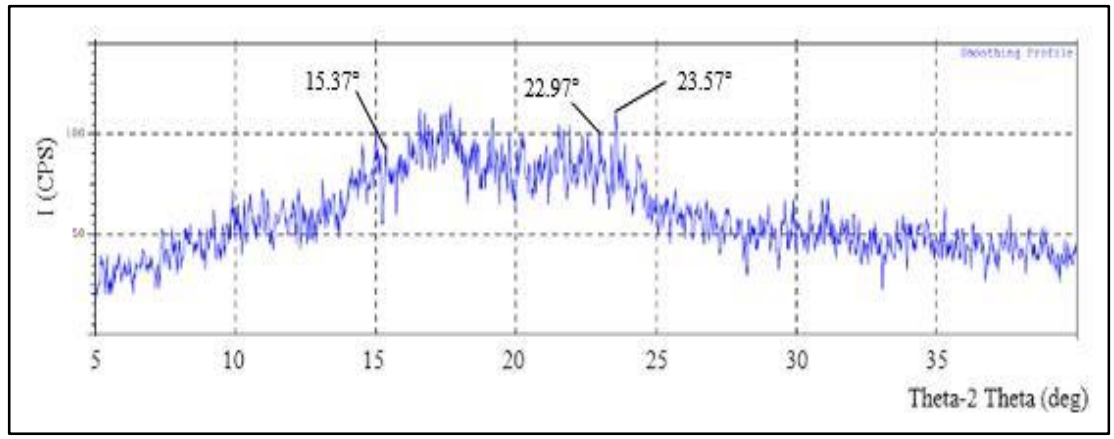

Figure 1. XRD diffractogram of jackfruit seed starch powder 


\section{Mechanical properties}

The addition of glycerol greatly affects the tensile strength (TS) and elongation at break (E\%) of TPS films. Figure 2 and Figure 3 show the effect of increasing the glycerol content of TPS films on tensile properties.

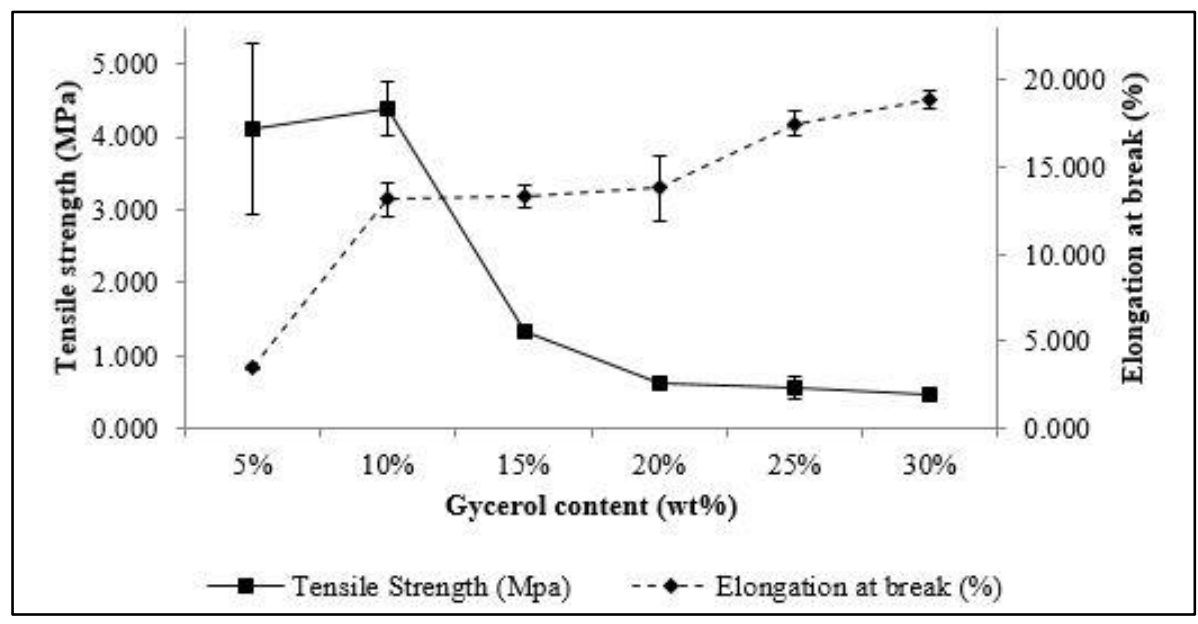

Figure 2. Effect of increasing glycerol content on the tensile properties of starch films

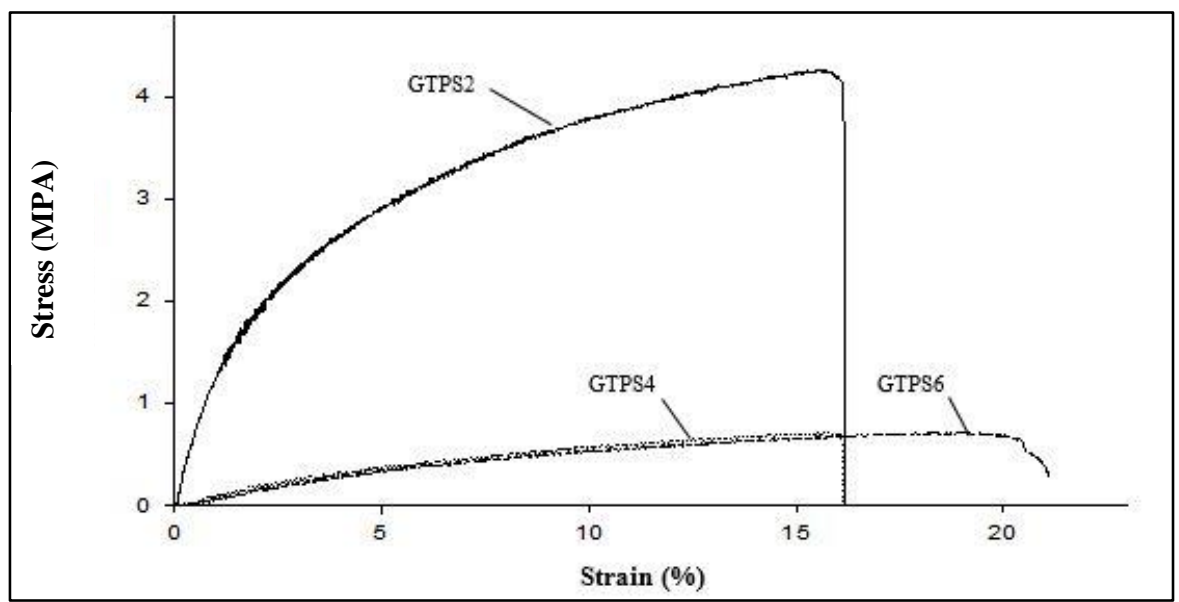

Figure 3. Effect of increasing the glycerol content on stress-strain curve of starch films

Starch film with less than 5\% glycerol was ignored due to brittleness. Starch film with the addition of 5\% glycerol showed a tensile strength of $4.12 \mathrm{MPa}$. The addition of $10 \%$ glycerol increased the TS of GTPS1 by $7 \%$, indicating that there is enough plasticizing effect. However, the addition of $15 \%$ of glycerol to GTPS 2 reduced the TS by almost $70 \%$ due to the plasticizing effect that is too prominent. On the other hand, the E\% of the films increased gradually by adding more concentration of glycerol into the starch. The results showed that with the increase in glycerol content from 5\% to $30 \%$ in the blend, the E\% increased to a large extent: $3.47 \%-18.88 \%$. In short, increasing glycerol concentration more than $10 \%$ on the JFSS will produce films that are more extendible as well as less rigid and stiff. This is depicted in Figure 2, which show a decrease of TS and an increase of the E\% of the films, respectively. These trends are probably due to the reduction in interactions between the starch chains, which caused the expansion of distance between starch molecules to allow the plasticizers to be embedded between them, thus forming a hydrogen bond between the glycerol and starch molecules. 
Furthermore, the tensile failure stress-strain curves in Figure 3 shows a more ductile character of the films with the increase in glycerol concentration. This was shown by the decrease of the film TS and an increase in flexibility as the glycerol concentration increased from $10 \%$ to $30 \%$. GTPS2 indicated high stress coupled with low strain, thus, were considered brittle. Increasing the concentration of glycerol improved the ductility of GTPS4 and GTPS6 films, which is revealed by their significant deformation before fracture. Sanyang et al. [6] also reported a similar trend based on the results obtained from using glycerol in sugar palm starch films. In fact, $10 \%$ glycerol delivered the highest TS of 4.40 MPa to the JFSS films, which can be associated with its homogeneous surface structure revealed by SEM and the formation of hydrogen bond evidenced by FTIR.

\section{Morphological structure}

The morphology of jackfruit seed starch granules and glycerol-plasticized starch films (magnification of 500x) were presented in Figure 4. Figure 4(a) shows that the starch granules have varied round shape with a smooth surface. As a result of the plasticization of jackfruit seed starch with 5\% and 10\% glycerol, less coarse granules were observed in Figure 4(b) - 4(c), probably due to the starch granule fusing into homogeneous phase. It is revealed that the surface of starch with $10 \%$ glycerol is clear and smooth without gross defects. This indicates that the starch molecules were well dispersed as not many granules were exposed to low glycerol content. Reddy and Yang [9] also found a similar morphology in glycerol-plasticized corn starch films. Increasing the glycerol content to more than $10 \%$ resulted in a rougher surface and the phase separation between glycerol and starch in blend films were clearly observed in Figure 4(d) - 4(g). The fact that the blend with $10 \%$ glycerol was very strong and has lower elongation compared to the blend with $30 \%$ glycerol may account for the appearance of such voids and cracks. It should be noted that the surface structure of thermoplastics is corroborated with the mechanical properties finding as discussed previously.

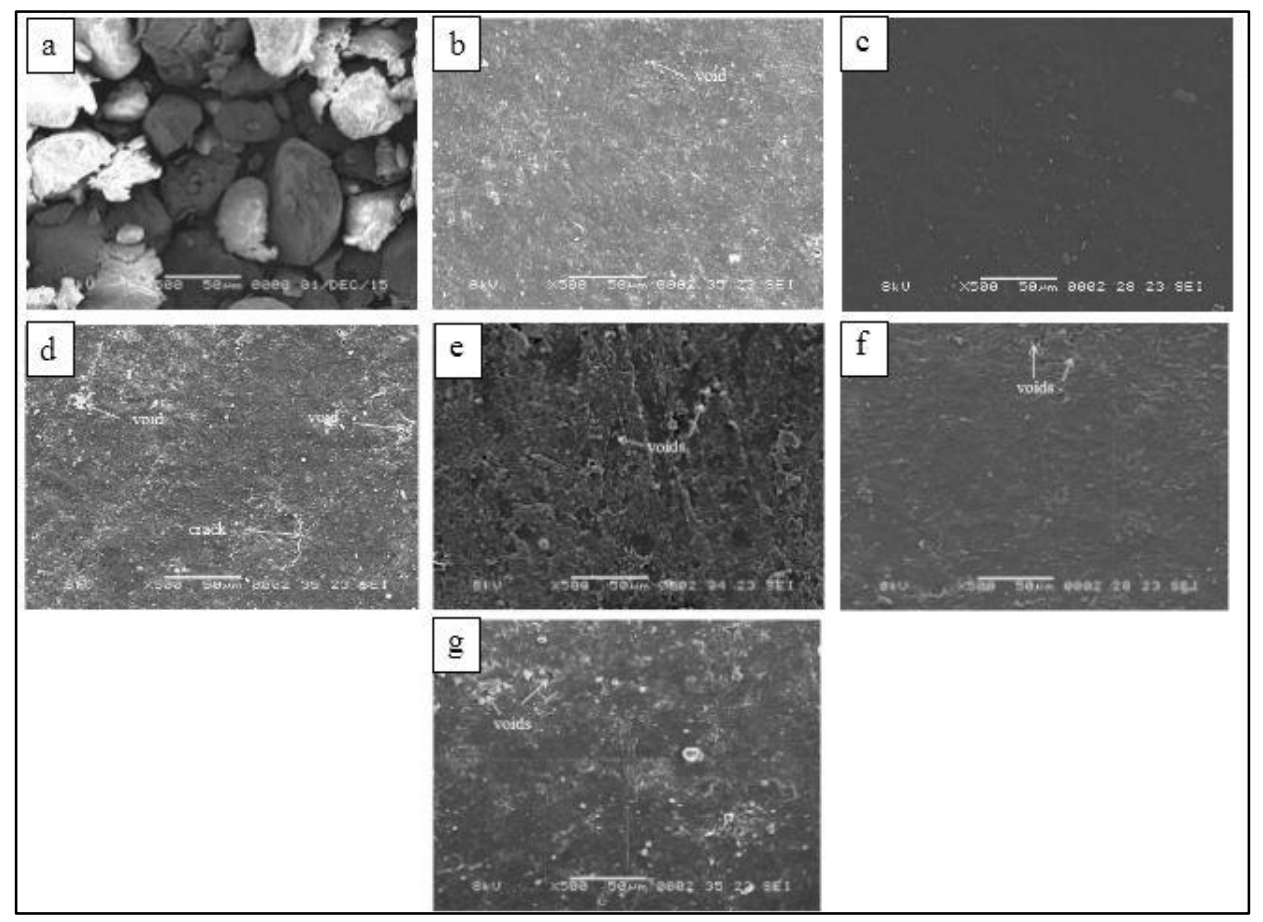

Figure 4. SEM micrographs of (a) JFSS powder, (b) 5 wt.\% glycerol (GTPS1), (c) 10 wt.\% glycerol (GTPS2), (d) 15 wt.\% glycerol (GTPS3), (e) 20 wt.\% glycerol (GTPS4), (f) 25 wt.\% glycerol (GTPS5), and (g) 30 wt.\% glycerol (GTPS6) films 
FTIR analysis

The FTIR spectra of the jackfruit seed starch granules and $10 \%$ glycerol-plasticized starch films are shown in Figure 5(a) and 5(b).

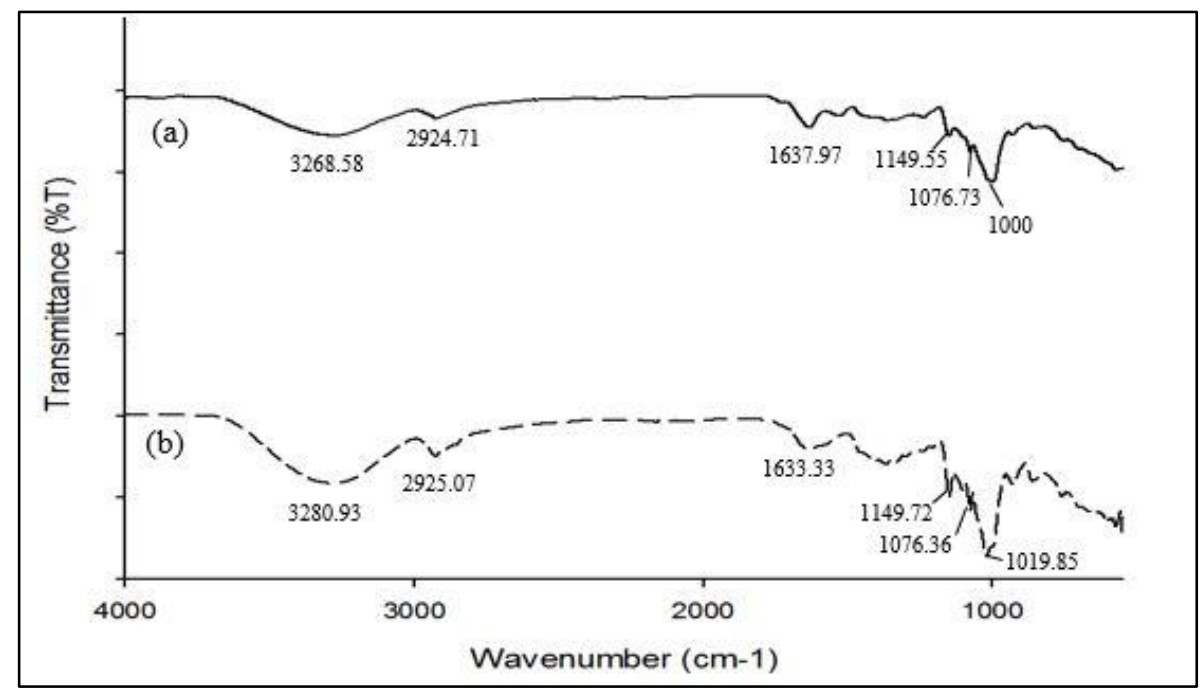

Figure 5. FTIR spectra for (a) JFSS powder and (b) GTPS2 film

The analysis of FTIR spectra of the $10 \%$ glycerol-plasticized film enabled the hydrogen bond interaction to be recognized compared to the native JFSS powder. For GTPS2, the characteristic peaks that were attributed to C-O bond stretching of C-O-H group were found to be shifted from $1076.73 \mathrm{~cm}^{-1}$ to $1076.36 \mathrm{~cm}^{-1}$ and $1149.55 \mathrm{~cm}^{-1}$ to $1149.72 \mathrm{~cm}^{-1}$. This indicates that the $\mathrm{O}-\mathrm{H}$ group of starch was encompassed in the hydrogen bond formation. Another peak, that was related to C-O bond stretching of C-O-C group at $1000 \mathrm{~cm}^{-1}$ became more prominent and presented a displacement to $1019.85 \mathrm{~cm}^{-1}$, could be regarded as the structure changes of JFSS from an amorphous to semi-crystalline state [11]. In sum, the appearance of characteristic peaks proved that glycerol could form hydrogen bond interaction with starch molecules. It is also believed that the formation of hydrogen bond in thermoplastic contributed to the improvement of mechanical properties as discussed earlier.

\section{Conclusion}

The difference in the amount of glycerol incorporated with jackfruit seed starch has been shown to have a substantial effect on the physical and mechanical properties of casted films. The increase in the glycerol content of more than $10 \%$ in jackfruit seed starch films improved its flexibility but reduced the strength. Starch film plasticized with 10\% glycerol achieved the highest strength, 4.40 MPa, and formed stable hydrogen bond interactions with the starch molecules. In addition, TPS produced from the native JFSS has homogeneous structure.

\section{Acknowledgement}

The authors would like to acknowledge the Research Management Centre, International Islamic University Malaysia for the research grant RIGS16-072-0236.

\section{References}

1. Nafchi, A. M., Moradpour, M., Saeidi, M. and Alias, A. K. (2013). Thermoplastic starches: Properties, challenges, and prospects. Starch/Stärke, 65(1-2): 61-72.

2. Noor, F., Rahman, J., Mahomud, S., Akter, M. S., Talukder, A. I. and Ahmed, M. (2014). Physicochemical properties of flour and extraction of starch from jackfruit seed. International Journal of Nutrition and Food Sciences, 3(4): 347-354. 
3. Hansen, M. C., Krylov, A. and Tyukavina, A. (2017). Utilization starch of jackfruit seed (Artocarpus heterophyllus) as raw material for bioplastics manufacturing using sorbitol as plasticizer and chitosan as filler. IOP Conference Series: Journal of Physics, 801(1): 012014.

4. Han, J. H. (2013). Innovations in food packaging. Academic Press, Canada: pp. 391-412.

5. Khan, B. Bilal, M., Niazi, K., Samin, G. and Jahan, Z. (2016). Thermoplastic starch : A possible biodegradable food packaging material - a review. Journal of Food Process Engineering, 40(3): 12447- 12452.

6. Sanyang, M. L., Sapuan, S. M., Jawaid, M., Ishak, M. R. and Sahari, J. (2015). Effect of plasticizer type and concentration on tensile, thermal and barrier properties of biodegradable films based on sugar palm (Arenga pinnata) starch. Polymers, 7(6): 1106-1124.

7. Retnowati, D. S., Ratnawati, R. and Purbasari, A. (2015). A biodegradable film from jackfruit (Artocarpus heterophyllus) and Durian (Durio zibethinus) seed flours. Scientific Study and Research, 16(4): 395-404.

8. Seligra, P. G., Jaramillo, C. M., Fama, L. and Goyanes, S. (2016). Biodegradable and non-retrogradable ecofilms based on starch-glycerol with citric acid as crosslinking agent. Carbohydrate Polymers, 138: 66-74.

9. Reddy, N. and Yang, Y. (2010). Citric acid cross-linking of starch films. Food Chemistry, 118(3): $702-711$.

10. Theivasanthi, T. and Alagar, M. (2011). An insight analysis of nano sized powder of jackfruit seed. Nano Biomedicine Engineering, 3(3): 163-168.

11. Ahmad, Z., Anuar, H. and Yusof, Y. (2011). The study of biodegradable thermoplastics sago starch. Key Engineering Materials, 471 - 472: 397-402. 